Review

\title{
Nuclear migration in mammalian brain development
}

\author{
Chiara Bertipaglia ${ }^{a}$, João Carlos Gonçalves ${ }^{a, b, c}$, Richard Bert Vallee ${ }^{a, *}$ \\ a Department of Pathology and Cell Biology, Columbia University, New York, NY 10032, United States \\ ${ }^{\mathrm{b}}$ Life and Health Sciences Research Institute (ICVS), School of Medicine, University of Minho, Braga, 4710-057, Portugal \\ ' ICVS/3B's-PT Government Associate Laboratory, Braga, Guimarães, Portugal
}

\section{A R T I C L E I N F O}

\section{Article history:}

Received 16 October 2017

Received in revised form

22 November 2017

Accepted 23 November 2017

Available online 6 December 2017

\section{Keywords:}

Nucleus

Migration

Nuclear envelope

Cytoskeleton

Microtubules

Centrosome

Molecular motors

\begin{abstract}
A B S T R A C T
During development of the mammalian brain, neural stem cells divide and give rise to adult stem cells, glia and neurons, which migrate to their final locations. Nuclear migration is an important feature of neural stem cell (radial glia progenitor) proliferation and subsequent postmitotic neuronal migration. Defects in nuclear migration contribute to severe neurodevelopmental disorders such as microcephaly and lissencephaly. In this review, we address the cellular and molecular mechanisms responsible for nuclear migration during the radial glia cell cycle and postmitotic neuronal migration, with a particular focus on the role of molecular motors and cytoskeleton dynamics in regulating nuclear behavior.
\end{abstract}

(c) 2017 Published by Elsevier Ltd.

\section{Contents}

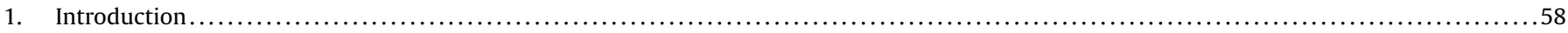

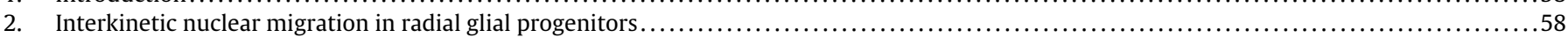

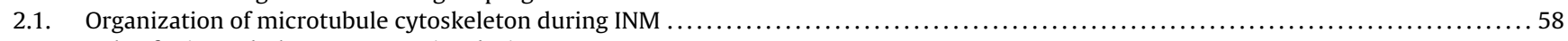

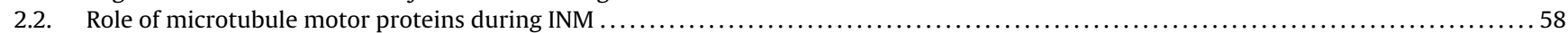

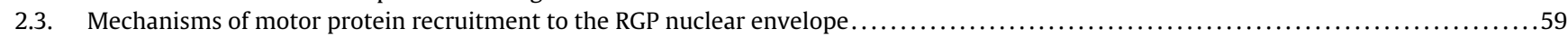

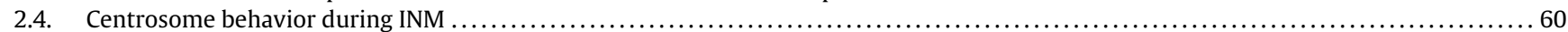

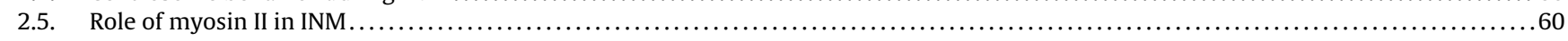

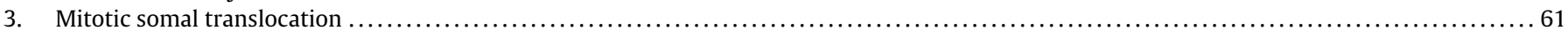

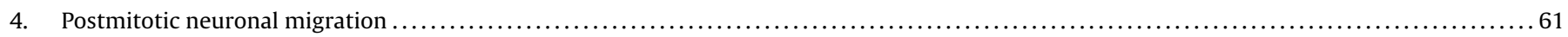

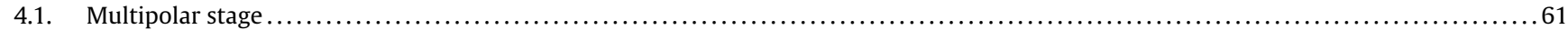

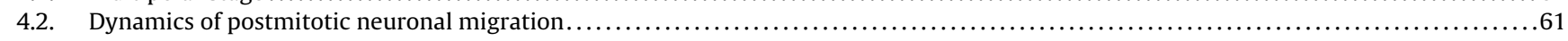

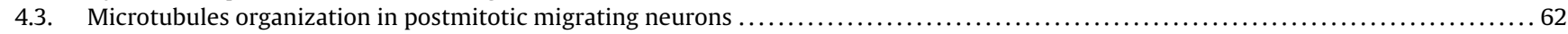

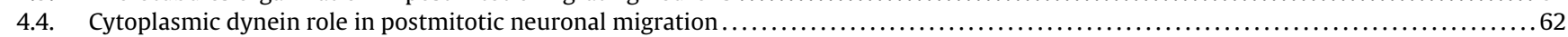

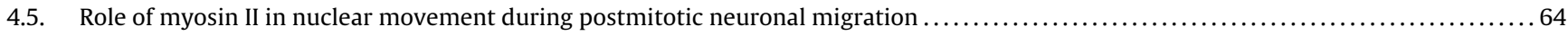

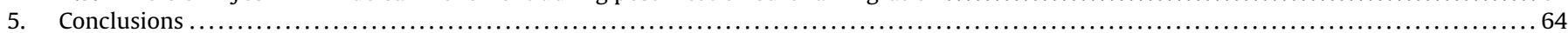

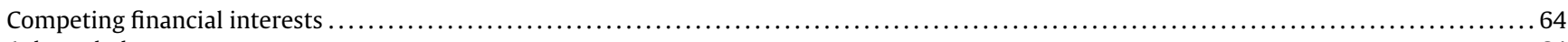

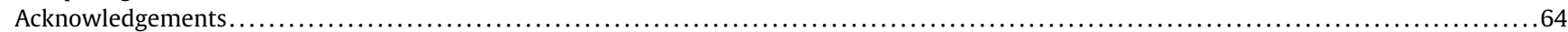

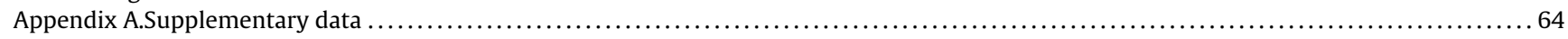

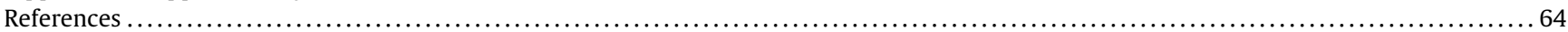

\footnotetext{
Abbreviations: NE, nuclear envelope; RGP, radial glia progenitor; INM, interkinetic nuclear migration; oRGC, outer radial glia cell; MST, mitotic somal translocation.

* Corresponding author.

E-mail address: rv2025@columbia.edu (R.B.Vallee).
} 


\section{Introduction}

Mammalian central nervous system development is a complex process requiring extensive nuclear movement and cell migration. During embryogenesis the neural plate, which is the precursor to the mammalian brain, folds to give rise to the neural tube, consisting of a pseudostratified neuroepithelium with stem-like properties [1]. The neuroepithelial cells are highly elongated and have a bipolar morphology, with the two processes spanning the distance between the pial and the ventricular surfaces of the cerebral neocortex $[2,3]$. In these cells the nucleus moves between the apical and basal surfaces of the neural tube. As brain development progresses, the basal process of the progenitor cells elongates, and the cells are now referred to as radial glial progenitors (RGPs). The nucleus of both the neuroepithelial and RGP cells exhibits an unusual form of cell cycle-dependent oscillatory behavior known as interkinetic nuclear migration (INM). Following mitosis at the ventricular surface, during G1 the nucleus migrates "basally" toward the subventricular zone. The RGP cell undergoes S-phase, and then the nucleus migrates "apically" during G2 to return to the lumen of the neural tube or, subsequently in development, the ventricular surface for the next mitotic division (Fig. 1 and Supplemental movie 1) [4,5].

The RGPs persist during most of cortical development, and have stem-like properties: they can divide either symmetrically, giving rise to new RGPs, or asymmetrically, generating intermediate progenitors or postmitotic neurons [3]. Intermediate progenitors do not exhibit INM nor have elongated processes, and reside in the subventricular zone, ultimately dividing to form two postmitotic neurons $[6,7]$. These cells then migrate toward the pial surface of the cortical plate, as discussed for postmitotic neurons in general below.

Nuclear migration during either neurogenesis or subsequent postmitotic neuronal migration is controlled by the cytoskeleton and involves the centrosome directly or indirectly. In this review, we discuss our current understanding of the cellular and molecular mechanisms that govern nuclear and centrosomal behavior in mammalian neuronal cells, with an emphasis on molecular motors and their regulatory factors and cargo adaptors.

\section{Interkinetic nuclear migration in radial glial progenitors}

Throughout the cell cycle the RGP nucleus exhibits an unusual form of oscillatory behavior, referred to as INM. Once the basal process has begun to elongate dramatically, nuclear migration distance of the RGP cell is limited to the ventricular zone. Mitosis is restricted to the ventricular surface, after which the nucleus moves basally. S-phase is thought to occur when the nucleus is away from the ventricle. Then, during G2 the nucleus returns apically to the ventricular surface where a new mitotic event takes place (Fig. 1 and Supplemental movie 1) [4,5].

Although the phenomenon of INM had been known for a long time [8-10], its developmental purpose and underlying mechanisms remained unknown. Live imaging analysis of INM in organotypic brain slice culture began to reveal the bidirectional behavior of individual RGP nuclei in detail [11-13]. Apical migration was found to be relatively fast though intermittent $\left(0.14 \pm 0.02 \mu \mathrm{m} \mathrm{min}^{-1}\right.$ with pauses of $0.5-2 \mathrm{~h}$ and bursts of up to $1 \mu \mathrm{mmin}^{-1}$ ) [13]. Basal migration was much slower $\left(0.063 \pm 0.009 \mu \mathrm{m} \mathrm{min}^{-1}\right)$ but continuous $[13,14]$, making it more difficult to characterize (Fig. 1b and Supplemental movie 1). Such different kinetics suggested the possibility of distinct motorbased mechanisms controlling the apical versus basal movement. Importantly, in each case, once initiated, nuclear migration was unidirectional.

\subsection{Organization of microtubule cytoskeleton during INM}

In view of evidence that microtubules might be involved in INM $[15,16]$, it seemed important to test the orientation of microtubules in the RGP cells. This was accomplished by expressing the microtubule-plus end tracking protein EB3, which associates predominantly with the growing microtubule end. Strikingly, microtubules were observed to be largely unidirectional in the RGP cells, with $93 \%$ showing their plus ends to be oriented basally (Fig. 1a) [13]. Thus, if nuclei were freely moving, directly along the microtubules, apical migration toward the centrosome would be expected to require cytoplasmic dynein, a minus end-directed motor protein, and basal migration a plus end-directed motor protein, perhaps one of the many kinesins.

In RGPs the restricted localization of the centrosome to the apical end of the cell also suggested that nuclei might migrate along microtubules under their own power, rather than being pulled along by the microtubule cytoskeleton

The centrosome remained exclusively associated with the apical end of the RGP throughout the cell cycle (Fig. 1a) [5,13]. The RGP nucleus departed from the centrosome during $\mathrm{G} 1$, and its entire excursion away from and back to the ventricular surface was virtually centrosome-independent.

\subsection{Role of microtubule motor proteins during INM}

The first direct evidence of a role for microtubule motor proteins in INM came from analysis of the effects of Lis1 RNAi in rat embryonic brain [15]. LIS1 is responsible for classic lissencephaly (smooth brain), a severe brain developmental disease [17]. It is also a key regulator of the microtubule minus-end directed molecular motor cytoplasmic dynein [18-21]. LIS1 had been speculated to participate in neuronal migration, to account for the more-or-less normal brain mass, but altered cortical lamination, of lissencephaly patients [17]. In utero electroporation of Lis1 shRNAs into embryonic rat brain revealed, in fact, a near complete arrest of postmitotic neuronal migration in rat embryonic brain [15]. In addition, it completely blocked INM in the RGP cells. These results suggested that Lis1 and, by extension, cytoplasmic dynein might be involved in INM, which was directly confirmed by later studies [5,13]. Indeed, In utero electroporation of rat embryonic brain with shRNA against dynein heavy chain abolished apical migration, though basal migration could still be detected [13].

Evidence for a role of motor proteins in INM was also reported in zebrafish retina, in which mutation or altered expression of p150 Glued, a component of the dynein regulatory complex dynactin, altered both basal and apical INM [22].

Despite evidence for a dynactin role in zebrafish basal INM, the orientation of microtubules in rat RGPs suggested a role for a microtubule plus end-directed motor, i.e., a kinesin, in basal INM. To test this possibility 11 rat plus end-directed kinesin heavy chains were screened for this role. Although several kinesins were found to contribute to over-all neuronal distribution, basal INM was specifically inhibited by knockdown of the kinesin 3 Kif1a [13]. An important consequence of this effect was accumulation of the nuclei near the ventricular surface, causing newborn nuclei to persist at the ventricular surface following mitosis [13]. Surprisingly, there was little effect on cell cycle progression, as judged by staining with cell cyclespecific markers. Live imaging of mitotic progression revealed that the inhibited RGP cells continued to divide [23]. Finally, the ratio of asymmetric to symmetric mitotic divisions was clearly reduced by Kif1a knockdown, leading to an increase in the ratio of progenitor cells to neurons. Furthermore, the orientation of the cytokinetic cleavage plane was remarkably shifted from horizontal to vertical, suggesting a role for Kif1a in mitotic spindle orientation [23], though this remains to be tested directly. 
a
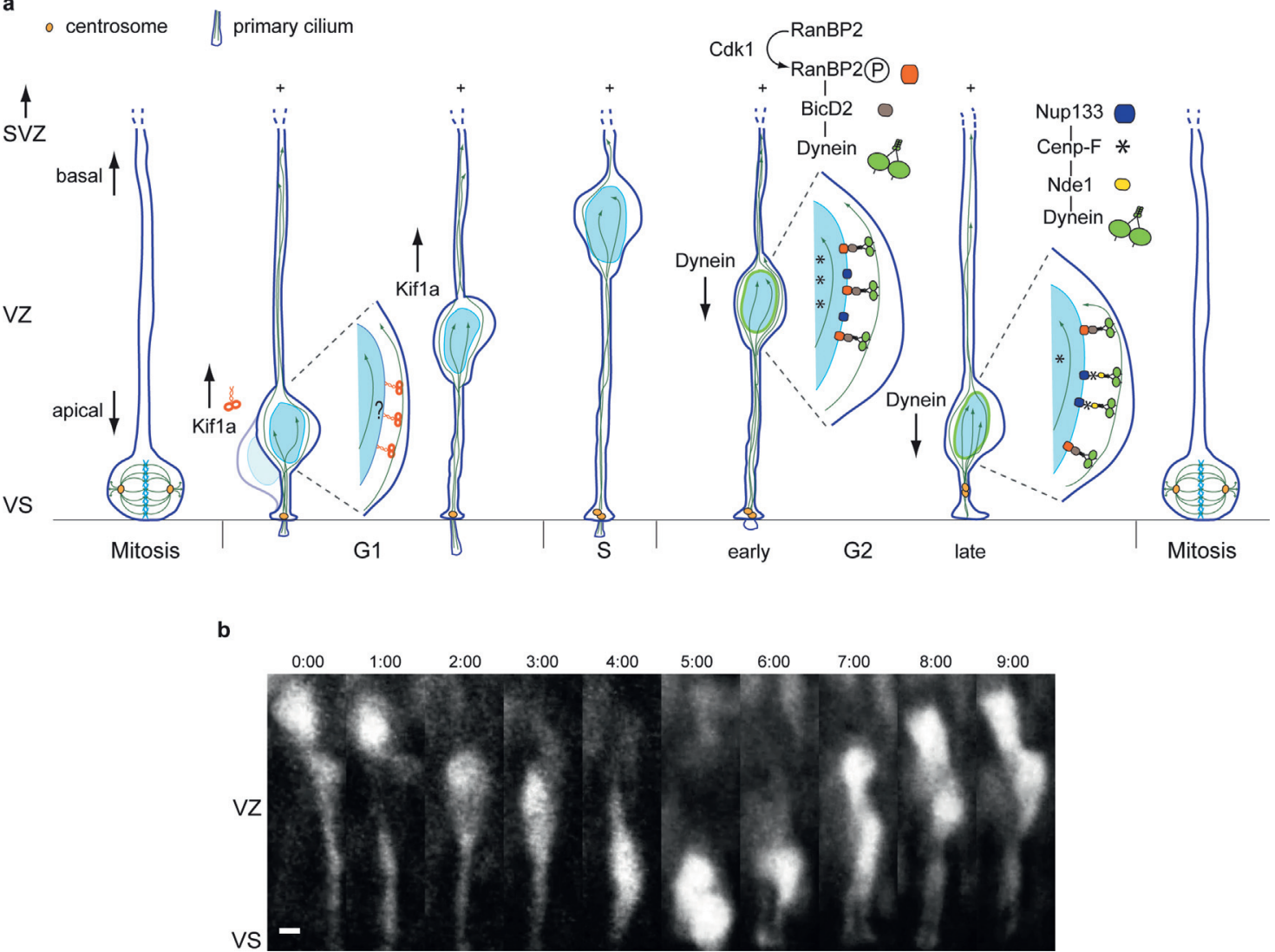

Fig. 1. INM of RGPs in the ventricular zone of the mammalian brain cortex.

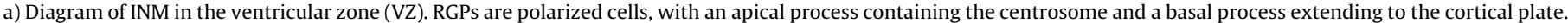

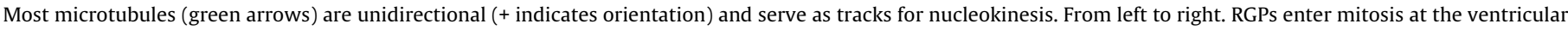

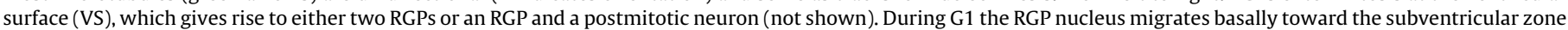

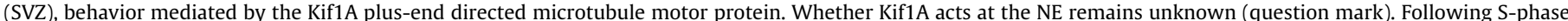

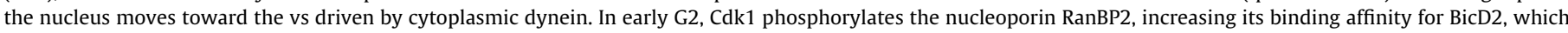

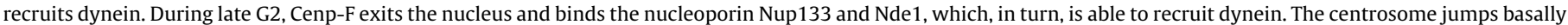
toward the nucleus before mitotic entry. Accumulation of dynein at the NE is shown in green.

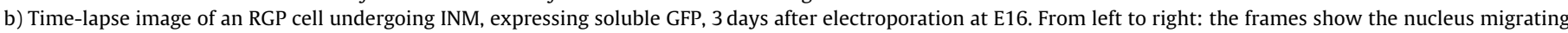

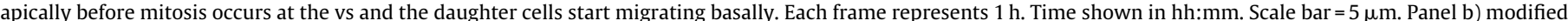
with permission from [89]. See supplemental movie 1 for full movie.

Human patients with KIF1A mutations have been found to develop an unusual progressive form of microcephaly [24]. Whether this effect is related to altered neurogenesis is unknown.

In addition to a direct role for motor proteins in nuclear migration in the developing brain, it has been speculated that basal INM might be driven via passive displacement by apically transported nuclei [14]. As a test of this hypothesis magnetic beads were introduced into the ventricular zone of embryonic mouse brain slices. The beads were observed to exhibit basal movements [14]. Despite these observations it is not clear how passive displacement could be sufficient to sustain long-range nuclear transport over $10 \mu \mathrm{m}$ or beyond.

\subsection{Mechanisms of motor protein recruitment to the RGP nuclear envelope}

Where within the RGP cell motor proteins might act emerged as an important new question. Because the nucleus travelled independently of the centrosome, it was speculated that dynein and Kif1a might associate with the RGP nuclear envelope (NE) and carry it along MTs as a very large membranous cargo. Another intriguing question was how this behavior might be entrained with cell cycle progression.
Cytoplasmic dynein had been found to decorate the NE through a number of mechanisms. Dynein was reported to decorate NE in nonneuronal cells during G2 $[25,26]$. Dynein was also deduced to exert force on the NE as revealed by the formation of prophase NE invaginations at the site of apposition to the centrosome in nonneuronal cells $[25,26]$ and in progenitor cells of the developing mouse cortex [27]. Although dynein is responsible for apical INM, an additional role in RGPs and other cell types in mitotic NE breakdown may be considered. Dynein is clearly non-essential for this role, as NE breakdown occurs in vitro independent of nocodazole treatment and microtubule disassembly. Nonetheless, evidence has been reported for a dynein role at this stage in physical disruption of the NE [25]. A requirement for cytoplasmic dynein in NE breakdown in RGPs has been difficult to address, and remains untested.

Two different mechanisms were subsequently implicated in early and late stages of $G 2$ dynein recruitment, involving the nucleoporins RanBP2 (Nup358) and Nup133 [28,29]. In early G2 RanBP2 recruits the dynein adaptor BicD2 which, in turn, recruits dynein, dynactin, and LIS1 to the NE [28]. In late G2 CENP-F exits the nucleus to bind Nup133 at the cytoplasmic surface of the NE. CENP-F then recruits Nde1 and Ndel1 $[29,30]$ which, in turn, recruit dynein and dynactin [30-33]. All cultured nonneuronal cells with CENPF-decorated NE were also positive for NE BicD2, but not vice versa, indicating that the two NE dynein recruitment pathways come into 
play sequentially, with the RanBP2-BicD2 pathway being activated earlier in G2 than the CENP-F one [5]. BicD2 and dynein were found to localize to the RGP NE in embryonic rat brain sections [5]. Knockdown of BicD2, Nup133, CENP-F or Nde1 each specifically blocked apical nuclear migration [5,34]. Consistent with the sequential activation of the two pathways, BicD2 knockdown arrested nuclei far from the ventricular surface [5]; whereas Nup133, CENP-F or Nde1 knockdown arrested nuclei close to the ventricular surface $[5,34]$. RGP nuclei blocked either early or late in apical INM in each case failed to enter mitosis [5,34]. Nevertheless, forced targeting of dynein to the NE by BicD2 overexpression dramatically rescued apical migration and mitotic progression. These results strongly supported the model where RGP nuclei must reach the ventricular surface for mitotic entry to occur [5].

How dynein might act on the nucleus in a cell cycle-regulated fashion remained to be investigated. To determine the mechanism controlling G2-specific dynein recruitment, rat brain slices were exposed to a specific inhibitor of the Cyclin-dependent kinase Cdk1, RO3306, which blocked G2 nuclear movement prior to apical migration. This treatment did not appear to perturb the velocity of basal migration during G1, arguing against a substantial role for passive nuclear displacement in basal migration. The Cdk1/Cdk5 inhibitor roscovitine interfered with both BicD2 and dynein localization to the RGP NE [35]. Indeed, in vitro phosphorylation analysis further revealed that Cdk1 phosphorylates the nucleoporin RanBP2 at five amino acid residues, increasing its binding affinity for BicD2, and thus initiating dynein recruitment to the NE in early G2 [35] (Fig. 1a).

A role for Cdk1 in the late G2 NE dynein recruitment pathway was also tested in HeLa cells. Cdk1 inhibition was shown to impair export of CENP-F from the nucleoplasm to the NE [35]. Moreover, Cdk1 phosphorylation on Nde1 has been found to stimulate its recruitment to the late $\mathrm{G} 2 \mathrm{NE}$ by an enhanced interaction with CENP-F (Wynne and Vallee, in revision). Cdk1 was also reported to phosphorylate Ndel1, thereby ensuring dynein presence at the $\mathrm{NE}$, in COS-7 cells [27].

Finally, Cdk1 has also been reported to be involved in cell cycleregulated nuclear migration of progenitors in zebrafish [36], though the molecular mechanism remains to be analyzed.

Unlike apical migration, for which the cell cycle regulatory aspect has been explored deeply, many unanswered questions remain concerning basal migration and the involvement of molecular motors. It is now known that Kif-1a pulls the nucleus basally, however its anchor at the NE and the molecular pathway that recruits it to the $\mathrm{NE}$ in a G1-specific fashion still remain to be elucidated.

Other anchors for molecular motors at the NE have been investigated over the past ten years. However, the relevance of the Linker of Nucleoskeleton and Cytoskeleton (LINC) complex in connecting molecular motors with the NE is unclear. Knockout mice for SUN and Nesprin proteins, components of the LINC complex, exhibited a moderate inhibition of INM $[37,38]$; nevertheless, it is not clear how the LINC complex might recruit the motors and how it would do it in a cell-cycle regulated manner. In contrast to these reports, later work using overexpression of a Klarsicht/ANC-1/Syne-1 homology (KASH) domain, to displace endogenous Nesprins from the NE, showed no effect on INM by live imaging in rat embryonic brain slices [5].

\subsection{Centrosome behavior during INM}

During interphase the RGP nucleus migrates independently of the centrosome, which remains at the apical end feet $[5,13,16,39,40]$ where it anchors a primary cilium $[34,41,42]$. However, in late G2, after the cilium axoneme is reabsorbed, the centrosome moves basally and reaches the nucleus (Fig. 1a). In the developing rat brain cortex, the centrosome departs basally to meet the apically migrating nucleus around $5 \mu \mathrm{m}$ away from the ventricular surface, and then together they complete the rest of apical migration, before NE breakdown takes place at the ventricular surface [5]. A different scenario was observed in chicken neural-tube-slice culture cells and in the mouse cerebral cortex [41], where microtubules were reported to be essential to drive the nucleus for $86 \%$ of the apical migration length, and actomyosin to be necessary to complete the remaining $14 \%$. In these systems NE breakdown occurred when the basally-migrating centrosome and apically-migrating nucleus met $14-17 \mu \mathrm{m}$ away from the ventricular surface, [41].

The trigger for RGP mitotic entry and NE breakdown at the ventricular surface and whether it is associated with the centrosome represent major questions in the field. The observations that the centrosome jumps to reach the nucleus and it is located at the site of mitotic initiation suggest a possible role for this structure in mitotic entry. In mitosis, the centrosome splits to form the spindle poles, an essential function in proper mitotic progression, but not clearly in mitotic initiation. Moreover, coexpression in embryonic rat brain of Nde1 RNAi with Ndel1, KASH-BicD2 (KASH domain of nesprin 3 fused to the dynein-interacting portion of BicD2), or BicD2 rescue arrested apical INM without initiating mitosis [34]. These results suggest that Nde1 may have a unique role in triggering mitotic entry, distinct from recruiting dynein to the NE. Thus, whether centrosome-nucleus contact or a centrosome-mediated signaling mechanism involving Nde1 is required for early mitotic events is yet to be elucidated.

\subsection{Role of myosin II in INM}

The involvement of actomyosin contractility in nuclear migration during INM of different systems has been a subject of debate. Treatment of Drosophila imaginal discs with the actin polymerization inhibitor latrunculin A caused nuclei to arrest 10 um away from the apical epithelial surface [43]. Moreover, staining with anti phospho-myosin regulatory chain 2 antibody revealed sign of myosin II activity at the cell cortex during rounding of the mitotic cell [43]. Nevertheless, incubation of chicken neural tube slices with cytochalasin $\mathrm{B}$, which inhibits actin polymerization, did not affect apical INM, nor the centrosome movement, but impeded cell rounding after NE breakdown [41]. In fact, in this system apical migration was reported to be dependent on microtubules, as it was blocked by the microtubule depolymerizing agent colcemid [41]. Live imaging of rat embryonic brain slices subjected to acute treatment with blebbistatin, a myosin II inhibitor, caused no observable effect on the velocity of nuclear movement during INM [13]. Opposite to this, blebbistatin was reported to inhibit basal INM in whole telencephalic hemispheres cultures, though this conclusion was based on fixed analysis of cohorts of RGP nuclei over time [44]. In Zebrafish neuroepithelial cells of the retina, actomyosin was proposed to be the main driver of INM [45], as INM was reported to persist in the presence of colcemid, but to cease in the presence of blebbistatin [12]. Nonetheless, mutation or inhibition of the Zebrafish dynactin subunit p150 ${ }^{\text {Glued }}$ was reported to affect both apical and basal nuclear migration in the same tissue. Despite the disparities in the results from different systems, we suspect that long-range ( $10 \mu \mathrm{m}$ or greater) nuclear migration will prove to be largely under the control of bidirectional microtubule motor proteins. Myosin II plays a role in postmitotic neuronal migration (see below) and, of course, in cytokinesis. In the INM system, it may contribute to spindle positioning or some other peri-mitotic behavior. 


\section{Mitotic somal translocation}

Especially in primates, RGPs can give rise to a recently identified type of progenitors described as the outer radial glial cells (oRGCs) [46]. Their number varies depending on the species; in primate brains these cells populate an entire region, known as the outer subventricular zone. These cells have lost contact with the ventricular surface of the developing brain, but retain a basal process reaching the pial surface [46]. Like RGPs, oRGCs can both self-renew and give rise to neurons [47]. However, they have been reported to display what appears to be a distinct nucleokinesis mechanism. Just prior to mitosis, their nucleus migrates outward through the basal process, behavior termed mitotic somal translocation (MST) [46]. Unlike INM in RGPs, the centrosomes associate with the nucleus throughout its translocation. Treatment of human fetal cortical slice cultures with blebbistatin and the inhibitor of the upstream myosin protein kinase ROCK completely inhibited MST. In contrast, the microtubule inhibitor nocodazole did not have effect on the translocation but inhibited mitosis. These results suggested that MST and mitosis are mechanistically distinct events, the former being regulated mainly by myosin II and the latter being dependent on microtubules [48].

The capability of oRGCs to divide and differentiate may account for the extra neurogenic source that could explain the evolutionary expansion of the human neocortex, compared to the majority of other mammalian species. Thus, the function of MST may be explained in the context of the evolution of the human brain. However, more research is needed to further our understanding of the precise molecular machinery that governs this form of nuclear migration behavior, and how its dependence on motor proteins relates to that in RGP cells and postmitotic neurons.

\section{Postmitotic neuronal migration}

\subsection{Multipolar stage}

Postmitotic neurons and intermediate progenitors originate from RGP cells at the ventricular surface and migrate to the subventricular zone/lower intermediate zone of the neocortex, where they assume a multipolar configuration extending and retracting multiple processes $[6,15]$. These have been reported to sense environmental cues that guide neuronal migration to the cortical plate [49]. One multipolar cell process continues to grow during further development, becoming the axon. Another process thickens to become the "migratory process" while the remaining processes retract, resulting in an over-all bipolar morphology. Then, bipolar cells start migrating radially along the fibers of the RGP cells (radial migration) (Fig. 2 and Supplemental movie 2) [13,15,23]. The centrosome has been reported to play an important role in the morphogenetic transition from the multipolar to the bipolar stage, first in specifying the axonal process and subsequently the migratory process, as the remaining processes retract [50-53]. Many other factors, including transcriptional regulators, small GTPases, protein kinases, neurotrophins, and proteins involved in cytoskeleton dynamics have been reported to contribute to the multipolar-to-bipolar transition, both cell-autonomously and non cell-autonomously[54-56].

Nevertheless, the molecular mechanisms triggering the multipolar-to-bipolar transition still remain largely unexplored. RNAi for Lis1, cytoplasmic dynein heavy chain [15], BicD2, CENP-F, Nup133 [5], Nde1 and Ndel1 [34] each caused accumulation of multipolar cells in the subventricular zone of the embryonic rat brain cortex. In particular, Lis1 and Kif1a shRNAs and dominant negative cDNAs, in utero electroporated into embryonic rat brain, were more directly found to cause arrest of neurons at the multi- polar stage, as judged by live imaging [15,23]. As these genes have been implicated in nuclear movement, defects in nuclear migration might also contribute to arrest at the multipolar-to-bipolar transition, though this possibility remains unexplored.

We suspect that inhibition of the cytoplasmic dynein pathway may interfere with the multipolar-to-bipolar transition by causing defects in the interaction between nucleus and centrosome. Kif1a inhibition resulted in particularly severe inhibition at the multipolar-to-bipolar transition. This normally gradual behavior was completely arrested as judged by direct monitoring over a two-day period [23]. The contributions of Kif1a appear to be complex. Given the role of this motor protein in basal INM, an involvement in nuclear behavior during the multipolar-bipolar transition seems a reasonable possibility. A further Kif1a role, however, is in neurotrophin secretion. Curiously, Kif1a inhibition caused cell nonautonomous arrest in many surrounding multipolar cells, suggesting interference with an intercellular communication mechanism [23]. The Kif1a-inhibited cells showed another surprising feature, expression of later neuronal differentiation markers, such as Tbr1 [23]. This suggested distinct Kif1a-dependent mechanisms, one contributing to the multipolar-to-bipolar morphogenetic change, and the other controlling neuronal gene expression.

As Kif1a had been implicated in the transport of dense-core vesicles [57], defects in neurotrophin secretion might be at issue. Indeed, application of recombinant BDNF to the brain slices largely rescued the cell-nonautonomous effects of Kif1a inhibition. Strikingly, the Kif1a cell-autonomous effects on morphogenesis and migration persisted [23]. These results suggested potential roles for Kif1a in nuclear or centrosome behavior, and an additional role in neurotrophin secretion. Several of these effects were reminiscent of those identified for the gene responsible for X-linked lissencephaly, doublecortin [58,59], a known Kif1a interactor [23,60]. Indeed, doublecortin knockdown phenocopied the effects of Kif1a inhibition [23], strongly supporting a common role for these genes $[23,60]$.

\subsection{Dynamics of postmitotic neuronal migration}

Once neurons have established an axon and a migratory process, they begin to migrate toward the cortical plate. Neurons originating at the ventricular surface in the cortex migrate radially to the cortical plate. Neurons arising at the lateral ganglionic eminence migrate by apparent similar mechanisms tangentially, perpendicular to the axis of the radial glia fibers. Radial neuronal migration involves movement along the basal process of the RGP: the cell body glides along the RGP fiber with cycles of release and re-establishment of neuron-glia adhesions (Fig. 3a) [61,62]. Migration continues until the migratory process reaches the pial surface of the marginal zone and becomes thicker and shorter [62] (Fig. 2 and Supplemental movie 2). Eventually, the soma detaches from the RGP fibers and the nucleus translocates within the remaining migratory process to its final destination within the cortical plate [63].

Tangential [64] and radial neuronal migration have been described as a "two-stroke" process: centrosome migration into the extended migratory process, followed by nuclear translocation (Fig. 3) $[50,51,64-70]$. Time-lapse imaging of neurons expressing centrosome and nuclear markers as they migrate in the developing rat neocortex has revealed further details of the dynamics of radial migration in live rat brain cortical slices [13] (Fig. 3b). A cytoplasmic swelling typically forms within the migratory process [71]. The centrosome then migrates into the swelling (Fig. 3a, middle panel) at a relatively constant rate $[64,65,67,71]$ but never passes it [71], suggesting that this might be the locus of the forces responsible for centrosome advance [71]. The nucleus follows the centrosome after a variable temporal and spatial gap (Fig. 3a, bottom panel). Nuclear movement can be strikingly saltatory, perhaps reflecting 


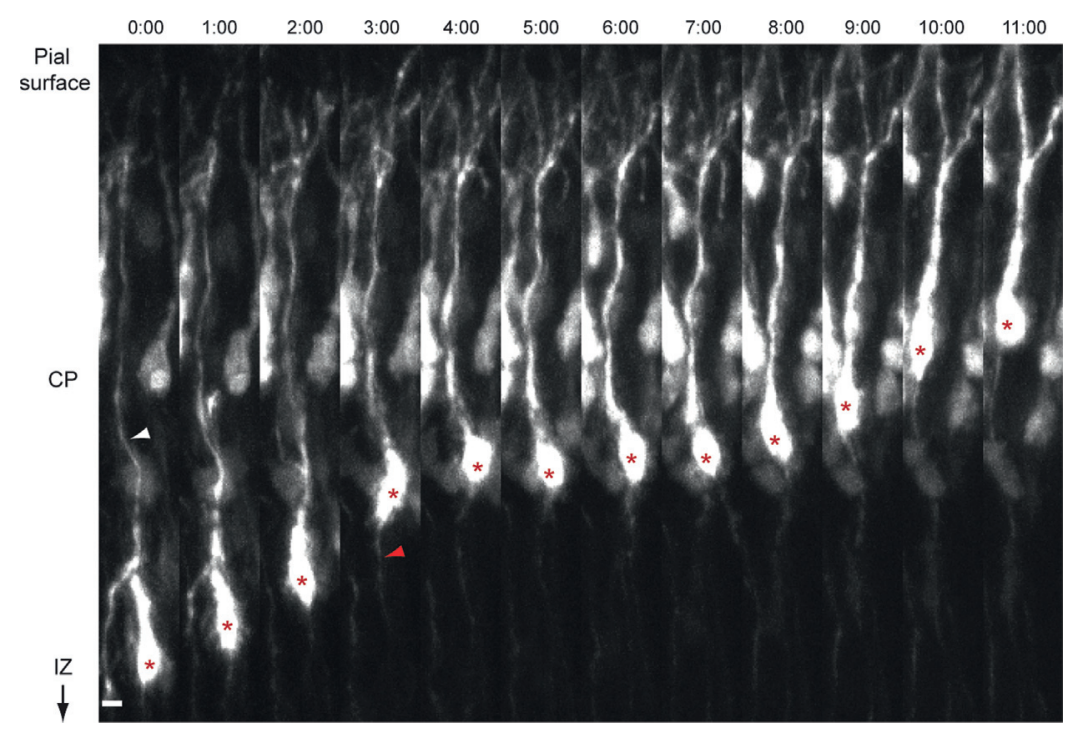

Fig. 2. Live imaging of radial postmitotic neuronal migration.

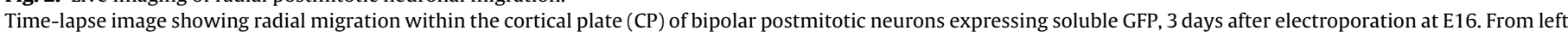

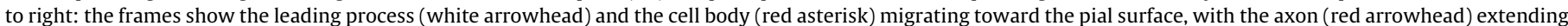

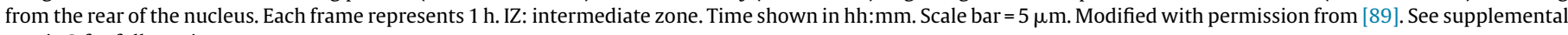
movie 2 for full movie.

the resistance to transport such a large structure through the much narrower migratory process [64,65,68,71].

The nature of the relationship between nucleus and centrosome is a long-standing and intriguing question. In both tangentially [64] and radially migrating postmitotic neurons, the centrosome tends to lead the nucleus $[67,68,71]$. This pattern may be reversible in radially migrating cerebellar neurons, where two opposite scenarios have been observed. In particular, Solecki and colleagues [68] presented time-lapse imaging of cultured granule cells showing that the centrosome migrates ahead of the nucleus. Conversely, another study in mouse cerebellar slices showed that the nucleus moved forward in a saltatory fashion often faster than the centrosome, thereby passing ahead of it [72].

\subsection{Microtubules organization in postmitotic migrating neurons}

Expression of the microtubule plus end-binding protein EB3 and DsRed-tagged centrin in radially migrating cortical neurons revealed a centrosome-centered radial array of dynamic microtubules, ahead of the nucleus, with unidirectional microtubules extending out into the migratory process (Fig. 3a) [71]. The microtubule network also extends rearward, surrounding the nucleus $[68,71,73]$ and further extending into the axon. The perinuclear microtubules may correspond to the previously described "cage" surrounding the nucleus, imaged by immunocytochemistry in isolated cerebellar granule cells $[68,74]$. We do note that both radial (centrosome attached) and non-radial microtubules were seen by electron microscopy imaging [75].

Not all of the microtubules in migrating neurons cells are dynamic. Staining with anti-acetylated tubulin revealed a pool of stable microtubules extending from the soma to the migratory process in radially migrating cerebellar granule neurons [72].

\subsection{Cytoplasmic dynein role in postmitotic neuronal migration}

Dynein and Lis1 have been found to play important independent roles during postmitotic neuronal migration [15,71]. Indeed, it was shown that in radially migrating neurons dynein and Lis1 regulate both centrosome movement and nuclear translocation in rat embryonic brain. RNAi for the cytoplasmic dynein heavy chain blocked nuclear migration completely [15,71], but the centrosome movement only partially, likely due to the stability of the large dynein heavy chain polypeptide. Immunofluorescence microscopy of individual neurons, allowed to migrate out of brain slices into Matrigel, showed an enhanced dynein signal in the soma and in the cytoplasmic swelling. The latter was independent of the presence of the centrosome, suggesting a concentrated dynein pool within the swelling (Fig. 3a). We speculate that dynein may be associated with the cell cortex within the swelling, in view of the association of this motor protein with the cell cortex during mitosis and migration of nonneuronal cells.

How dynein might propel nuclear movement is uncertain, although, given its role in apical INM in RGPs, a potential role for dynein at the NE of migrating neurons seems reasonable. Knockdown of genes involved in dyneinmediated apical INM does cause accumulation of multipolar cells in the subventricular zone $[5,15,34]$. Whether this reflects residual effects of delayed INM, or some persistent role for NE dynein recruitment factors postmitotically, is uncertain. Some of these factors might, potentially, play a role in dynein recruitment to the NE of postmitotic neurons, but evidence for such a role at this stage is lacking.

The nesprins and SUN proteins are also candidates for a role in dynein NE recruitment $[37,76,77]$. The LINC complex was reported to be the main mediator connecting the nucleus to the cytoskeleton in migrating postmitotic neurons (Fig. 3a, bottom panel) [37]. Indeed, Nesprin-1/2 and SUN1/2 were found to be important for proper neurodevelopment [37]. In humans, Nesprin-1 mutations have been associated with neurological disorders $[78,79]$ and Sun $1^{-/-}$Sun2 $2^{-/-}$as well as Syne-1-/-Syne-2-/- double knockout mice died perinatally displaying cortical lamination defects. Live imaging of mouse brain slices revealed a marked decrease in the migration velocity of postmitotic neurons, indicating a role for the LINC complex in fundamental aspects of embryonic development, particularly for proper radial migration [37]. Overexpression in embryonic rat brain of a truncated KASH domain of Nesprin2 also impaired radial neuronal migration velocity, by $\sim 90 \%$ [5]. Immunoprecipitation of Nesprin-2 from brain cytosolic lysates was found to bind to either kinesin or the dynein-dynactin complex [37]. Nonetheless, the details of a dynein-Nesprin interaction in migrating neurons remain to be fully elucidated. 


\section{Migratory process extension}

adhesion
molecules centrosome microtubules

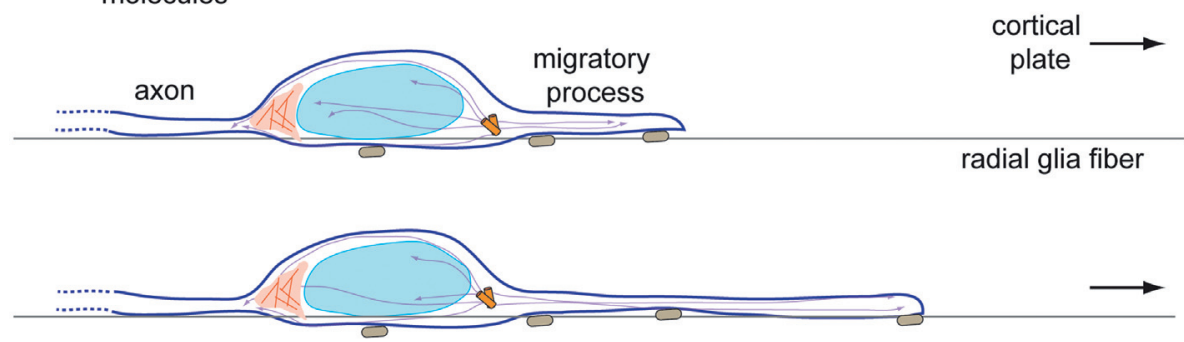

\section{Centrosome advance}

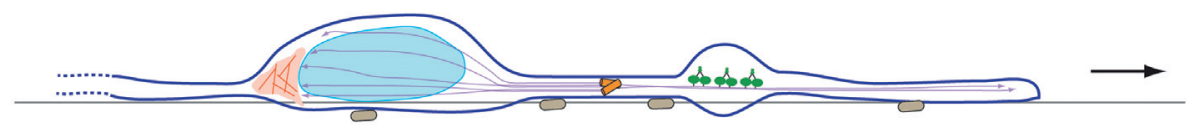

\section{Nuclear translocation}

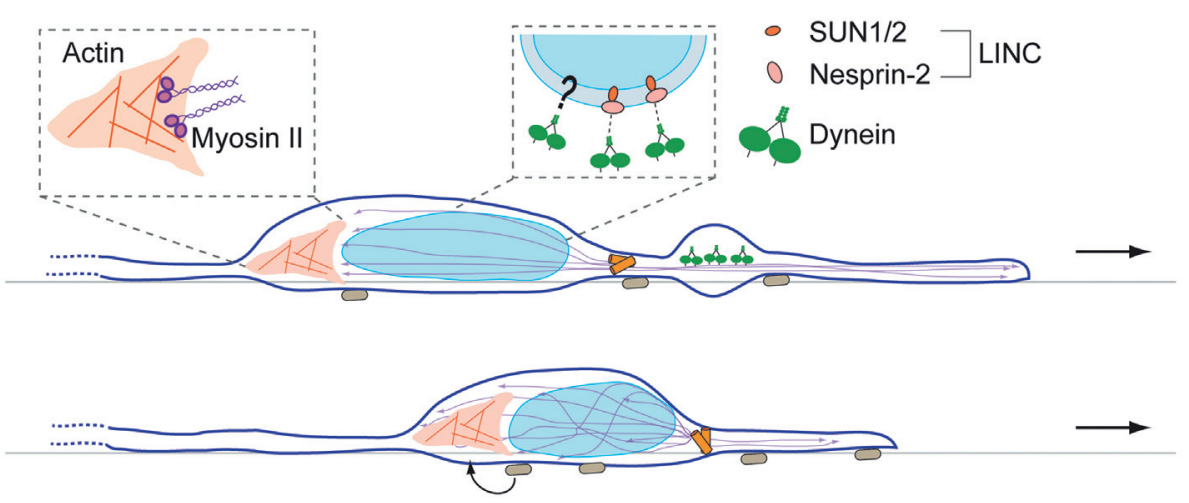

b

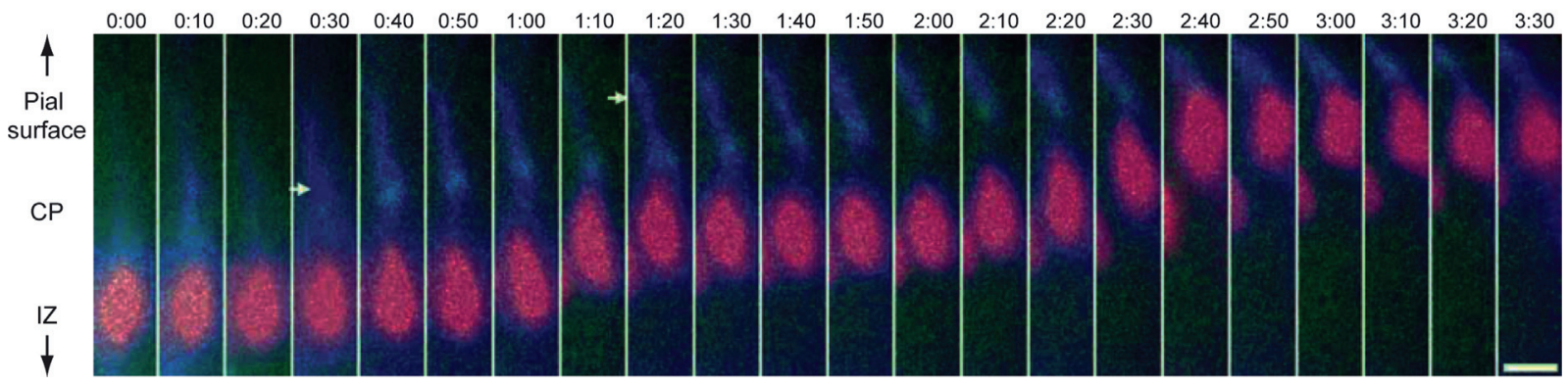

Fig. 3. Model for radial postmitotic neuronal migration.

a) Postmitotic neurons migrate to the cortical plate along the radial glia processes, with which they interact intermittently via adhesion molecules. Dynein localizes to the cytoplasmic swelling. It is thought that dynein pulls the entire centrosome-associated microtubule cytoskeleton forward. Nuclear translocation is mediated by NE-associated dynein pulling on the surrounding microtubules. Current evidence indicates that the LINC complex serves to recruit dynein to the NE at this stage, though the recruitment mechanisms have not yet been elucidated. Roles for nucleoporin-mediated dynein recruitment remain possible. Actomyosin contractility helps the nuclear translocation process from the rear of the nucleus. Eventually, the nucleus re-acquires its normal shape and the cycle continues with a new round of migratory process extension. Adhesion molecules are recycled throughout the process of forward translocation. To date, it is not clear whether the microtubules in the axon are orphan or nucleated by the centrosome.

b) Time-lapse image showing radial migration of a bipolar postmitotic neuron expressing soluble GFP (blue) staining the cytoplasm, DsRed-centrin II (green) staining the centrosome and CFP-H1 (red) staining the nucleus, within the cortical plate, 3 days after electroporation at E16. From left to right: frames show forward movement of the centrosome into the cytoplasmic swelling and nuclear translocation happening sequentially. Frames 0:40 to 1:10 display nuclear distortion during nucleokinesis. Each frame represents $10 \mathrm{~min}$. CP: cortical plate; IZ: intermediate zone. Time shown in hh:mm. Scale bar $=5 \mu \mathrm{m}$. Modified with permission from [71]. 


\subsection{Role of myosin II in nuclear movement during postmitotic neuronal migration}

Non-muscle myosin II has also been implicated in nuclear movement during postmitotic neuronal migration. Blebbistatin treatment halted the movement of isolated neurons in culture or Matrigel [67]. In contrast to the effects on nuclear behavior, myosin II RNAi and blebbistatin treatment in brain slices had no clear effect on centrosome movement, resulting in migration arrest with the centrosome far ahead of the nucleus [71].

To determine where myosin II acts in the cell, immunostaining with an antibody specific for the phosphorylated myosin light chain was performed. Active myosin was located at the rear of the nucleus, suggesting that myosin contraction might propel the nucleus forward [67]. More recent evidence has indicated that actin also accumulates in this region during migration, and that the actin meshwork contracts substantially until nuclear advance is over [80]. Altogether, these experiments have suggested a causal link between actomyosin contraction at the rear of the nucleus and nuclear movement. Hence, it has been proposed that, together with dynein-mediated pulling along the microtubules, myosin II-exerted force would push the nucleus forward through the constriction between the soma and the cytoplasmic dilation, thus contributing to nucleokinesis (Fig. 3a, bottom panel). Furthermore, dynein and myosin forces are each necessary for nuclear advance in migrating neurons.

Actin and myosin II presence has also been demonstrated in the leading migratory process of isolated cerebellar granule cell migrating in vitro [69]. FRAP experiments revealed that myosin II stimulates actin turnover rate in this region, and myosin inhibition was found to affect both centrosome and nuclear movement [69].

\section{Conclusions}

In the past ten years there has been considerable progress in our understanding of the mechanisms responsible for nuclear movement during brain development. These forms of behavior are now known to be governed by the cytoskeleton, both microtubules and actin filaments, and their molecular motors. Several genes encoding migration proteins are now known to be involved in human developmental diseases. These include, so far, Nde1 [81], Ndel1 [82], Lis1 [17,83], kinesin-1 Kif5c, kinesin-13 Kif2a, and tubulin [84], dynein heavy chain [84-86], doublecortin [87], kinesin-3 Kif1a [88]. Future work promises to identify additional disease genes involved in nuclear and neuronal migration, as well as in behavioral conditions not yet known to have a developmental component.

\section{Competing financial interests}

The authors declare no competing interests.

\section{Acknowledgements}

The authors thank Dr. Tiago Dantas and Dr. Aditi Falnikar for critical reading of the manuscript. This work was supported by grants R01 HD40182 to R.V., and the FCT MDPhD Scholarship PD/BD/113766/2015 to J.C.G.

\section{Appendix A. Supplementary data}

Supplementary data associated with this article can be found, in the online version, at https://doi.org/10.1016/j.semcdb.2017.11. 033.

\section{References}

[1] T.E. Anthony, C. Klein, G. Fishell, N. Heintz, Radial glia serve as neuronal progenitors in all regions of the central nervous system, Neuron 41 (2004) 881-890, http://dx.doi.org/10.1016/S0896-6273(04)00140-0.

[2] T.J. Dantas, A. Carabalona, D.J.-K. Hu, R.B. Vallee, Emerging roles for motor proteins in progenitor cell behavior and neuronal migration during brain development, Cytoskeleton (Hoboken) 73 (2016) 566-576, http://dx.doi.org/ $10.1002 / \mathrm{cm} .21293$.

[3] A. Kriegstein, A. Alvarez-Buylla, The glial nature of embryonic and adult neural stem cells, Annu. Rev. Neurosci. 32 (2009) 149-184, http://dx.doi.org/ 10.1146/annurev.neuro.051508.135600.

[4] E. Taverna, W.B. Huttner, Neural progenitor nuclei IN motion, Neuron 67 (2010) 906-914, http://dx.doi.org/10.1016/j.neuron.2010.08.027.

[5] D.J.-K. Hu, A.D. Baffet, T. Nayak, A. Akhmanova, V. Doye, R.B. Vallee, Dynein recruitment to nuclear pores activates apical nuclear migration and mitotic entry in brain progenitor cells, Cell 154 (2013) 1300-1313, http://dx.doi.org/ 10.1016/j.cell.2013.08.024.

[6] S.C. Noctor, V. Martínez-Cerdeño, L. Ivic, A.R. Kriegstein, Cortical neurons arise in symmetric and asymmetric division zones and migrate through specific phases, Nat. Neurosci. 7 (2004) 136-144, http://dx.doi.org/10.1038/nn1172.

[7] W. Haubensak, A. Attardo, W. Denk, W.B. Huttner, Neurons arise in the basal neuroepithelium of the early mammalian telencephalon: a major site of neurogenesis, Proc. Natl. Acad. Sci. 101 (2004) 3196-3201, http://dx.doi.org/ 10.1073 /pnas.0308600100.

[8] F.C. Sauer, Mitosis in the neural tube, J. Comp. Neurol. 62 (1935) 377-405, http://dx.doi.org/10.1002/cne.900620207.

[9] F.C. Sauer, The interkinetic migration of embryonic epithelial nuclei, J. Morphol. 60 (1936) 1-11, http://dx.doi.org/10.1002/jmor.1050600102.

[10] M.E. Sauer, B.E. Walker, Radioautographic study of interkinetic nuclear migration in the neural tube, Exp. Biol. Med. 101 (1959) 557-560, http://dx doi.org/10.3181/00379727-101-25014.

[11] S.C. Noctor, A.C. Flint, T.A. Weissman, R.S. Dammerman, Neurons derived from radial glial cells establish radial units in neocortex, Nature 409 (2001) 714-720.

[12] C. Norden, S. Young, B.A. Link, W.A. Harris, Actomyosin is the main driver of interkinetic nuclear migration in the retina, Cell 138 (2009) 1195-1208, http://dx.doi.org/10.1016/j.cell.2009.06.032.

[13] J.-W. Tsai, W.-N. Lian, S. Kemal, A.R. Kriegstein, R.B. Vallee, Kinesin 3 and cytoplasmic dynein mediate interkinetic nuclear migration in neural stem cells, Nat. Neurosci. 13 (2010) 1463-1471, http://dx.doi.org/10.1038/nn.2665.

[14] Y. Kosodo, T. Suetsugu, M. Suda, Y. Mimori-Kiyosue, K. Toida, S.A. Baba, A. Kimura, F. Matsuzaki, Regulation of interkinetic nuclear migration by cell cycle-coupled active and passive mechanisms in the developing brain, EMBO J. 3081 (2011) 1690-1704, http://dx.doi.org/10.1038/emboj.2011.81.

[15] J.-W. Tsai, Y. Chen, A.R. Kriegstein, R.B. Vallee, LIS1 RNA interference blocks neural stem cell division, morphogenesis, and motility at multiple stages, J. Cell Biol. 170 (2005) 935-945, http://dx.doi.org/10.1083/jcb.200505166.

[16] Z. Xie, L.Y. Moy, K. Sanada, Y. Zhou, J.J. Buchman, L.H. Tsai, Cep120 and TACCs control interkinetic nuclear migration and the neural progenitor pool, Neuron 56 (2007) 79-93, http://dx.doi.org/10.1016/j.neuron.2007.08.026.

[17] R. Reiner, Y. Carrozzo, M. Shen, F. Wehnert, W.B. Faustinella, C.T. Dobyns, D.H. Caskey, Isolation of a Miller-Dicker lissencephaly gene containing $G$ protein $\beta$-subunit-like repeats, Nature 364 (1993) 717-721, http://dx.doi.org/10. 1038/364717a0.

[18] N.E. Faulkner, D.L. Dujardin, C.-Y. Tai, K.T. Vaughan, C.B.O. 'connell, Y.-L. Wang, R.B. Vallee, A role for the lissencephaly gene LIS1 in mitosis and cytoplasmic dynein function, Nat. Cell Biol. 2 (2000).

[19] S. Sasaki, A. Shionoya, M. Ishida, M.J. Gambello, J. Yingling, A. Wynshaw-Boris, A LIS1/NUDEL/cytoplasmic dynein heavy chain complex in the developing and adult nervous system, Neuron 28 (2000) 681-696.

[20] D.S. Smith, M. Niethammer, R. Ayala, Y. Zhou, M.J. Gambello, A. Wynshaw-Boris, L.-H. Tsai, Regulation of cytoplasmic dynein behaviour and microtubule organization by mammalian Lis1, Nat. Cell Biol. 2 (2000) $767-775$.

[21] R.J. McKenney, M. Vershinin, A. Kunwar, R.B. Vallee, S.P. Gross, LIS1 and NudE induce a persistent dynein force-producing state, Cell 141 (2010) 304-314, http://dx.doi.org/10.1016/j.cell.2010.02.035.

[22] F. Del Bene, A.M. Wehman, B.A. Link, H. Baier, Regulation of neurogenesis by interkinetic nuclear migration through an apical-basal notch gradient, Cell 134 (2008) 1055-1065, http://dx.doi.org/10.1016/j.cell.2008.07.017.

[23] A. Carabalona, D.J.-K. Hu, R.B. Vallee, KIF1A inhibition immortalizes brain stem cells but blocks BDNF-mediated neuronal migration, Nat. Neurosci. 19 (2016) 253-262, http://dx.doi.org/10.1038/nn.4213.

[24] S. Esmaeeli Nieh, M.R.Z. Madou, M. Sirajuddin, B. Fregeau, D. Mcknight, K. Lexa, J. Strober, C. Spaeth, B.E. Hallinan, N. Smaoui, J.G. Pappas, T.A. Burrow, M.T. Mcdonald, M. Latibashvili, E. Leshinsky-Silver, D. Lev, L. Blumkin, R.D. Vale, A.J. Barkovich, E.H. Sherr, De novo mutations in KIF1A cause progressive encephalopathy and brain atrophy, Ann. Clin. Transl. Neurol. 2 (2015) 623-635, http://dx.doi.org/10.1002/acn3.198.

[25] J.L. Beaudouin, D. Gerlich, N. Daigle, R. Eils, J. Ellenberg, Nuclear envelope breakdown proceeds by microtubule-induced tearing of the lamina, Cell 108 (2002) 83-96. 
[26] D. Salina, K. Bodoor, D.M. Eckley, T.A. Schroer, J.B. Rattner, B. Burke, Cytoplasmic dynein as a facilitator of nuclear envelope breakdow, Cell 108 (2002) 97-107.

[27] S. Hebbar, M.T. Mesngon, A.M. Guillotte, B. Desai, R. Ayala, D.S. Smith, Lis1 and Ndel1 influence the timing of nuclear envelope breakdown in neural stem cells, J. Cell Biol. 182 (2008) 1063-1071, http://dx.doi.org/10.1083/jcb. 200803071.

[28] D. Splinter, M.E. Tanenbaum, A. Lindqvist, D. Jaarsma, A. Flotho, K. Lou Yu, I Grigoriev, D. Engelsma, E.D. Haasdijk, N. Keijzer, J. Demmers, M. Fornerod, F. Melchior, C.C. Hoogenraad, R.H. Medema, A. Akhmanova, D.2 Bicaudal, Dynein, and kinesin-1 associate with nuclear pore complexes and regulate centrosome and nuclear positioning during mitotic entry, PLoS Biol. 8 (2010) e1000350, http://dx.doi.org/10.1371/journal.pbio.1000350.

[29] S. Bolhy, I. Bouhlel, E. Dultz, T. Nayak, M. Zuccolo, X. Gatti, R. Vallee, J. Ellenberg, V. Doye, A Nup133-dependent NPC-anchored network tethers centrosomes to the nuclear envelope in prophase, J. Cell Biol. 192 (2011) 855-871, http://dx.doi.org/10.1083/jcb.201007118.

[30] M.A.S. Vergnolle, S.S. Taylor, Cenp-F links kinetochores to Ndel1/Nde1/Lis1/Dynein microtubule motor complexes, Curr. Biol. 17 (2007) 1173-1179, http://dx.doi.org/10.1016/j.cub.2007.05.077.

[31] S.A. Stehman, Y. Chen, R.J. McKenney, R.B. Vallee, NudE and NudEL are required for mitotic progression and are involved in dynein recruitment to kinetochores, J. Cell Biol. 178 (2007) 583-594, http://dx.doi.org/10.1083/jcb. 200610112.

[32] E. Zyłkiewicz, M. Kijańska, W.-C. Choi, U. Derewenda, Z.S. Derewenda, P.T. Stukenberg, The N-terminal coiled-coil of Ndel1 is a regulated scaffold that recruits LIS1 to dynein, J. Cell Biol. 192 (2011) 433-445, http://dx.doi.org/10. 1083 jicb.201011142.

[33] Y. Liang, W. Yu, Y. Li, L. Yu, Q. Zhang, F. Wang, Z. Yang, J. Du, Q. Huang, X. Yao, $\mathrm{X}$. Zhu, Nudel modulates kinetochore association and function of cytoplasmic dynein in M phase, Mol. Biol. Cell. 18 (2007) 2656-2666, http://dx.doi.org/10 1091/mbc.E06.

[34] D.J. Doobin, S. Kemal, T.J. Dantas, R.B. Vallee, Severe NDE1-mediated microcephaly results from neural progenitor cell cycle arrests at multiple specific stages, Nat. Commun. 7 (2016) 12551, http://dx.doi.org/10.1038/ ncomms12551.

[35] A.D. Baffet, D.J.-K. Hu, R.B. Vallee, Cdk1 activates pre-mitotic nuclear envelope dynein recruitment and apical nuclear migration in neural stem cells, Dev. Cell. 33 (2015) 1-14, http://dx.doi.org/10.1016/j.devcel.2015.04.022.

[36] L. Leung, A.V. Klopper, S.W. Grill, W.A. Harris, C. Norden, Apical migration of nuclei during G2 is a prerequisite for all nuclear motion in zebrafish neuroepithelia, Development 139 (2012) 5003-5013, http://dx.doi.org/10. $1242 /$ dev.085456.

[37] X. Zhang, K. Lei, X. Yuan, X. Wu, Y. Zhuang, T. Xu, R. Xu, M. Han, SUN1/2 and syne/Nesprin-1/2 complexes connect centrosome to the nucleus during neurogenesis and neuronal migration in mice, Neuron 64 (2009) 173-187, http://dx.doi.org/10.1016/j.neuron.2009.08.018.

[38] J. Yu, K. Lei, M. Zhou, C.M. Craft, G. Xu, T. Xu, Y. Zhuang, R. Xu, M. Han, KASH protein Syne-2/Nesprin-2 and SUN proteins SUN1/2 mediate nuclear migration during mammalian retinal development, Hum. Mol. Genet. 20 (2011) 1061-1073, http://dx.doi.org/10.1093/hmg/ddq549.

[39] A. Chenn, Y.A. Zhang, B.T. Chang, S.K. Mcconnell, Intrinsic polarity of mammalian neuroepithelial cells, Mol. Cell. Neurosci. 11 (1998) 183-193.

[40] X. Wang, J.-W. Tsai, J.H. Imai, W.-N. Lian, R.B. Vallee, S.-H. Shi, Asymmetric centrosome inheritance maintains neural progenitors in the neocortex, Nature 461 (2009), http://dx.doi.org/10.1038/nature08435.

[41] P.C. Spear, C.A. Erickson, Apical movement during interkinetic nuclear migration is a two-step process, Dev. Biol. 370 (2012) 33-41, http://dx.doi. org/10.1016/j.ydbio.2012.06.031.

[42] M. Paridaen, W.B. Wilsch-Brä uninger, Asymmetric inheritance of centrosome- associated primary cilium membrane directs ciliogenesis after cell division, Cell 155 (2013) 333-344, http://dx.doi.org/10.1016/j.cell.2013. 08.060 .

[43] E.J. Meyer, A. Ikmi, M.C. Gibson, Report interkinetic nuclear migration is a broadly conserved feature of cell division in pseudostratified epithelia, Curr. Biol. 21 (2011) 485-491, http://dx.doi.org/10.1016/j.cub.2011.02.002.

[44] J. Schenk, M. Wilsch-Bräuninger, F. Calegari, W.B. Huttner, Myosin II is required for interkinetic nuclear migration of neural progenitors, Proc. Natl. Acad. Sci. U. S. A. 106 (2009) 16487-16492, http://dx.doi.org/10.1073/pnas. 0908928106.

[45] M. Lahne, J. Li, R.M. Marton, D.R. Hyde, Actin-cytoskeleton- and rock-mediated INM are required for photoreceptor regeneration in the adult zebrafish retina, J. Neurosci. 35 (2015) 15612-15634, http://dx.doi.org/10. 1523/JNEUROSCI. 5005-14.2015.

[46] D.V. Hansen, J.H. Lui, P.R.L. Parker, A.R. Kriegstein, Neurogenic radial glia in the outer subventricular zone of human neocortex, Nature 464 (2010) 554-561, http://dx.doi.org/10.1038/nature08845.

[47] B.E. LaMonica, L.J.H. Hansen, A.R. Kriegstein, Mitotic spindle orientation predicts outer radial glial cell generation in human neocortex, Nat. Commun. 4 (2013) 1665, http://dx.doi.org/10.1038/ncomms2647.

[48] B.E.L. Ostrem, J.H. Lui, C.C. Gertz, A.R. Kriegstein, Control of outer radial glial stem cell mitosis in the human brain, Cell Rep. 8 (2014) 656-664, http://dx. doi.org/10.1016/j.celrep.2014.06.058.

[49] M. Valiente, O. Marín, Neuronal migration mechanisms in development and disease, Curr. Opin. Neurobiol. 20 (2010) 68-78, http://dx.doi.org/10.1016/j. conb.2009.12.003.
[50] F.C. de Anda, G. Pollarolo, J.S. da Silva, P.G. Camoletto, F. Feiguin, C.G. Dotti, Centrosome localization determines neuronal polarity, Nature 436 (2005) 704-708, http://dx.doi.org/10.1038/nature03811.

[51] D.J. Solecki, E.E. Govek, T. Tomoda, M.E. Hatten, Neuronal polarity in CNS development, Genes Dev. 20 (2006) 2639-2647, http://dx.doi.org/10.1101/ gad.1462506.

[52] F.C. de Anda, K. Meletis, X. Ge, D. Rei, L.-H. Tsai, Centrosome motility is essential for initial axon formation in the neocortex, J. Neurosci. 30 (2010) 10391-10406, http://dx.doi.org/10.1523/JNEUROSCI.0381-10.2010.

[53] A. Sakakibara, T. Sato, R. Ando, N. Noguchi, M. Masaoka, T. Miyata, Dynamics of centrosome translocation and microtubule organization in neocortical neurons during distinct modes of polarization, Cereb. Cortex. 24 (2014) 1301-1310, http://dx.doi.org/10.1093/cercor/bhs411.

[54] C. Ohtaka-Maruyama, H. Okado, Molecular pathways underlying projection neuron production and migration during cerebral cortical development, Front. Neurosci. 9 (2015) 447, http://dx.doi.org/10.3389/fnins.2015.00447.

[55] J.A. Cooper, Molecules and mechanisms that regulate multipolar migration in the intermediate zone, Front. Cell. Neurosci. 8 (2014) 386, http://dx.doi.org/ 10.3389/fncel.2014.00386.

[56] A.P. Barnes, F. Polleux, Establishment of axon-Dendrite polarity in developing neurons, Annu. Rev. Neurosci. 32 (2009) 347-381, http://dx.doi.org/10.1146/ annurev neuro.31.060407.125536.

[57] M. Kondo, Y. Takei, N. Hirokawa, Motor protein KIF1A is essential for hippocampal synaptogenesis and learning enhancement in an enriched environment, Neuron 73 (2012) 743-757, http://dx.doi.org/10.1016/j.neuron. 2011.12.020.

[58] J. Bai, R.L. Ramos, J.B. Ackman, A.M. Thomas, R.V. Lee, J.J. LoTurco, RNAi reveals doublecortin is required for radial migration in rat neocortex, Nat. Neurosci. 6 (2003) 1277-1283, http://dx.doi.org/10.1038/nn1153.

[59] R.L. Ramos, J. Bai, J.J. LoTurco, Heterotopia formation in rat but not mouse neocortex after RNA interference knockdown of DCX, Cereb. Cortex. 16 (2006) 1323-1331, http://dx.doi.org/10.1093/cercor/bhj074.

[60] J.S. Liu, C.R. Schubert, X. Fu, F.J. Fourniol, J.K. Jaiswal, A. Houdusse, C.M. Stultz, C.A. Moores, C.A. Walsh, Molecular basis for specific regulation of neuronal kinesin-3 motors by doublecortin family proteins, Mol. Cell. 47 (2012) 707-721, http://dx.doi.org/10.1016/j.molcel.2012.06.025.

[61] J.A. Cooper, Mechanisms of cell migration in the nervous system, Cell Differ. 15 (2013) 1-15, http://dx.doi.org/10.1016/0045-6039(84)90024-1.

[62] T. Kawauchi, Cellullar insights into cerebral cortical development: focusing on the locomotion mode of neuronal migration, Front. Cell. Neurosci. 9 (2015) 394, http://dx.doi.org/10.3389/fncel.2015.00394.

[63] K. Kawauchi, M. Sekine, K. Shikanai, K. Chihama, K. Tomita, K. ichiro Kubo, Y Nakajima, M. ichi Nabeshima, Rab GTPases-dependent endocytic pathways regulate neuronal migration and maturation through $\mathrm{N}$-cadherin trafficking, Neuron 67 (2010) 588-602, http://dx.doi.org/10.1016/j.neuron.2010.07.007.

[64] A. Bellion, J-P. Baudoin, C. Alvarez, M. Bornens, C. Métin, Nucleokinesis in tangentially migrating neurons comprises two alternating phases: forward migration of the Golgi/centrosome associated with centrosome splitting and myosin contraction at the rear, J. Neurosci. 25 (2005) 5691-5699, http://dx. doi.org/10.1523/JNEUROSCI.1030-05.2005.

[65] L.-H. Tsai, J.G. Gleeson, B.A. Samuels, H. Shih, L.H. Tsai, C.C. Mello, J.R. Priess, K.J. Kemphues, A. Wynshaw-Boris, M.E. Ross, C.A. Walsh, Nucleokinesis in neuronal migration, Neuron 46 (2005) 383-388, http://dx.doi.org/10.1016/j. neuron.2005.04.013.

[66] B. Nadarajah, J.E. Brunstrom, J. Grutzendler, R.O. Wong, A.L. Pearlman, Two modes of radial migration in early development of the cerebral cortex, Nat. Neurosci. 4 (2001) 143-150.

[67] B.T. Schaar, S.K. McConnell, Cytoskeletal coordination during neuronal migration, Proc. Natl. Acad. Sci. U. S. A. 102 (2005) 13652-13657, http://dx. doi.org/10.1073/pnas.0506008102.

[68] D.J. Solecki, L. Model, J. Gaetz, T.M. Kapoor, M.E. Hatten, Par6alpha signaling controls glial-guided neuronal migration, Nat. Neurosci. 7 (2004) 1195-1203, http://dx.doi.org/10.1038/nn1332.

[69] D.J. Solecki, N. Trivedi, E.E. Govek, R.A. Kerekes, S.S. Gleason, M.E. Hatten, Myosin II motors and F-actin dynamics drive the coordinated movement of the centrosome and soma during CNS glial-guided neuronal migration, Neuron 63 (2009) 63-80, http://dx.doi.org/10.1016/j.neuron.2009.05.028.

[70] R.B. Vallee, G.E. Seale, J.W. Tsai, Emerging roles for myosin II and cytoplasmic dynein in migrating neurons and growth cones, Trends Cell Biol. 19 (2009) 347-355, http://dx.doi.org/10.1016/j.tcb.2009.03.009.

[71] J.W. Tsai, K.H. Bremner, R.B. Vallee, Dual subcellular roles for LIS1 and dynein in radial neuronal migration in live brain tissue, Nat. Neurosci. 10 (2007) 970-979, http://dx.doi.org/10.1038/nn1934.

[72] H. Umeshima, T. Hirano, M. Kengaku, Microtubule-based nuclear movement occurs independently of centrosome positioning in migrating neurons, Proc. Natl. Acad. Sci. U. S. A. 104 (2007) 16182-16187, http://dx.doi.org/10.1073/ pnas.0708047104.

[73] Z. Xie, K. Sanada, B.A. Samuels, H. Shih, L.-H. Tsai, Serine 732 phosphorylation of FAK by cdk 5 is important for microtubule organization, nuclear movement, and neuronal migration, Cell 114 (2003) 469-482.

[74] R.J. Rivas, M.E. Hatten, Motility and cytoskeletal organization of migrating cerebellar granule neurons, J. Neurosci 15 (1995) 981-989.

[75] A.N. Rao, A. Falnikar, E.T. O'Toole, M.K. Morphew, A. Hoenger, M.W. Davidson, X. Yuan, P.W. Baas, Sliding of centrosome-unattached microtubules defines key features of neuronal phenotype, J. Cell Biol. 213 (2016) 329-341, http:// dx.doi.org/10.1083/jcb.201506140. 
[76] H.N. Fridolfsson, D.A. Starr, Kinesin-1 and dynein at the nuclear envelope mediate the bidirectional migrations of nuclei, J. Cell Biol. 191 (2010) 115-128, http://dx.doi.org/10.1083/jcb.201004118.

[77] R. Zhu, S. Antoku, G.G. Gundersen, Centrifugal displacement of nuclei reveals multiple LINC complex mechanisms for homeostatic nuclear positioning, Curr. Biol. 0 (2017), http://dx.doi.org/10.1016/j.cub.2017.08.073.

[78] F. Gros-Louis, N. Dupré, P. Dion, M.A. Fox, S. Laurent, S. Verreault, J.R. Sanes, J.-P. Bouchard, G.A. Rouleau, Mutations in SYNE1 lead to a newly discovered form of autosomal recessive cerebellar ataxia, Nat. Genet. 39 (2007) 80-85, http://dx.doi.org/10.1038/ng1927.

[79] M. Synofzik, K. Smets, M. Mallaret, D. Di Bella, C. Gallenmüller, J. Baets, M. Schulze, S. Magri, E. Sarto, M. Mustafa, T. Deconinck, T. Haack, S. Züchner, M. Gonzalez, D. Timmann, C. Stendel, T. Klopstock, A. Durr, C. Tranchant, M. Sturm, W. Hamza, L. Nanetti, C. Mariotti, M. Koenig, L. Schöls, R. Schüle, P. De Jonghe, M. Anheim, F. Taroni, P. Bauer, SYNE1 ataxia is a common recessive ataxia with major non-cerebellar features: a large multi-centre study, Brain 139 (2016) 1378-1393, http://dx.doi.org/10.1093/brain/aww079.

[80] F.J. Martini, M. Valdeolmillos, Actomyosin contraction at the cell rear drives nuclear translocation in migrating cortical interneurons, J. Neurosci. 30 (2010) 8660-8670, http://dx.doi.org/10.1523/JNEUROSCI.1962-10.2010.

[81] F.S. Alkuraya, X. Cai, C. Emery, G.H. Mochida, M.S. Al-Dosari, J.M. Felie, R.S. Hill, B.J. Barry, J.N. Partlow, G.G. Gascon, A. Kentab, M. Jan, R. Shaheen, Y. Feng, C.A. Walsh, Human mutations in NDE1 cause extreme microcephaly with lissencephaly, Am. J. Hum. Genet. 88 (2011) 536-547, http://dx.doi.org/10. 1016/j.ajhg.2011.04.003.

[82] Y. Ozeki, T. Tomoda, J. Kleiderlein, A. Kamiya, L. Bord, K. Fujii, M. Okawa, N. Yamada, M.E. Hatten, S.H. Snyder, C. a Ross, A. Sawa, Disrupted-in-Schizophrenia-1 (DISC-1): mutant truncation prevents binding to NudE-like (NUDEL) and inhibits neurite outgrowth, Proc. Natl. Acad. Sci. U. S. A. 100 (2003) 289-294, http://dx.doi.org/10.1073/pnas.0136913100.

[83] W.B. Dobyns, O. Reiner, R. Carrozzo, D.H. Ledbetter, Lissencephaly, A human brain malformation associated with deletion of the LIS1 gene located at chromosome 17p13, JAMA 270 (1993) 2838, http://dx.doi.org/10.1001/jama. 1993.03510230076039 .
[84] K. Poirier, N. Lebrun, L. Broix, G. Tian, Y. Saillour, C. Boscheron, E. Parrini, S. Valence, B. Saintpierre, M. Oger, D. Lacombe, D. Geneviève, E. Fontana, F. Darra, A. Andrieux, F. Francis, R. Guerrini, N.J. Cowan, N. Bahi-Buisson, J. Chelly, Mutations in TUBG1, DYNC1H1, KIF5C and KIF2A cause malformations of cortical development and microcephaly, Nat. Genet. 45 (2013) 639-647, http://dx.doi.org/10.1038/ng.2613.

[85] K.M. Ori-McKenney, R.B. Vallee, Neuronal migration defects in the Loa dynein mutant mouse, Neural Dev. 6 (2011) 26, http://dx.doi.org/10.1186/17498104-6-26.

[86] C. Fiorillo, F. Moro, J. Yi, S. Weil, G. Brisca, G. Astrea, M. Severino, A. Romano, R. Battini, A. Rossi, C. Minetti, C. Bruno, F.M. Santorelli, R. Vallee, Novel dynein DYNC1H1 neck and motor domain mutations link distal spinal muscular atrophy and abnormal cortical development, Hum. Mutat. 35 (2014) 298-302, http://dx.doi.org/10.1002/humu.22491.

[87] J.G. Gleeson, K.M. Allen, J.W. Fox, E.D. Lamperti, S. Berkovic, I. Scheffer, E.C. Cooper, W.B. Dobyns, S.R. Minnerath, M.E. Ross, C.A. Walsh, Doublecortin, a brain-specific gene mutated in human X-linked lissencephaly and double cortex syndrome, encodes a putative signaling protein, Cell 92 (1998) 63-72.

[88] S.S. Jamuar, A.-T.N. Lam, M. Kircher, A.M. D’Gama, J. Wang, B.J. Barry, X. Zhang, R.S. Hill, J.N. Partlow, A. Rozzo, S. Servattalab, B.K. Mehta, M. Topcu, D. Amrom, E. Andermann, B. Dan, E. Parrini, R. Guerrini, I.E. Scheffer, S.F. Berkovic, R.J. Leventer, Y. Shen, B.L. Wu, A.J. Barkovich, M. Sahin, B.S. Chang, M. Bamshad, D.A. Nickerson, J. Shendure, A. Poduri, T.W. Yu, C.A. Walsh, Somatic mutations in cerebral cortical malformations, N. Engl. J. Med. 371 (2014) 733-743, http://dx.doi.org/10.1056/NEJMoa1314432.

[89] A.D. Baffet, A. Carabalona, T.J. Dantas, D.D. Doobin, D.J.-K. Hu, R.B. Vallee, Cellular and subcellular imaging of motor protein-based behavior in embryonic rat brain, Methods Cell Biol. 131 (2016) 349-363, http://dx.doi. org/10.1016/bs.mcb.2015.06.013. 